\title{
Land subsidence and managed aquifer recharge in Pingtung Plain, Taiwan
}

\author{
Cheh-Shyh Ting ${ }^{1}$, Kou-Feng Chiang ${ }^{2}$, Sheng-Hsin Hsieh ${ }^{2}$, Chi-Hung Tsao ${ }^{3}$, Chi-Hung Chuang ${ }^{4}$, and \\ Kang-Teng Fan $^{4}$ \\ ${ }^{1}$ Department of Civil Engineering, Centre for Water Resources Educations and Studies, \\ National Pingtung University of Science and Technology, Pingtung 912, Taiwan \\ ${ }^{2}$ Water Resources Department, Pingtung County Government, Pingtung, Taiwan \\ ${ }^{3}$ Pingtung County Government, Pingtung, Taiwan \\ ${ }^{4}$ Pro. Vision Environmental Engineering Corporation (PVEEC), Taipei, Taiwan \\ Correspondence: Cheh-Shyh Ting (csting@ mail.npust.edu.tw)
}

Published: 27 April 2020

\begin{abstract}
Taiwan is an oceanic nation with an area of approximately $36000 \mathrm{~km}^{2}$. The Central Mountain Range was formed by the Eurasian and Philippine plates and stretches along the entire island from north to south, along the entire island, thus forming a natural line of demarcation for rivers on the eastern and western sides of the island. Pingtung Plain is formed by Quaternary alluvial fan material from the three main rivers. The aquifers comprise very coarse permeable sands and gravels under phreatic conditions in the north and less permeable sands under confined or even artesian conditions in the southern part of Pingtung Plain. The natural groundwater source is mainly from direct rainfall percolation and infiltration from the three main rivers, with their catchments lying partly outside the plain. The uncontrolled development of groundwater resources has led to undesirable effects, especially in the south, where aquaculture is concentrated. These effects are land subsidence, saline water intrusion, and lowering of water tables. It is thus one of the important key strategies in the solution of land subsidence, water resource development and flood control for sustainable development named Benefited Water Reuse from Storm Water in Pingtung, Taiwan. A serious of studies for this issue has been carried out. The feasibility study phase of the Artificial Recharge of Groundwater Project (ARGP) for Pingtung, Taiwan, was then implemented in 1997 using a MODFLOW simulation and an optimal model. Through the managed aquifer recharge model, the aquifer storage increases and the inundation scale decreases with land subsidence of the coastal area, as aimed at by the purpose of the controlled groundwater level. Infiltration mechanism simulation of artificial groundwater recharge, with the TOUGH2 model, was used to simulate the high infiltration behaviour in sequence in 2010. Both publications have been confirmed and approved by the Central Government and then approved by the environmental impact assessment. The ARGP was then implemented in May 2018 and operated for one wet season for the first phase with 50 ha and a total of 300 ha from May to October 2018. The sedimentation over the top of the recharge basin forms the clogging mechanism which has been analysed. The operation experience can further provide the mechanism process for research reference. The project, once implemented, can improve and mitigate land subsidence as well as formulate water banks for adapting and managing aquifer recharge.
\end{abstract}




\section{Introduction}

A series of studies for solving the land subsidence of coastal Taiwan and increasing water demand for multi-purpose issues has been carried out in Pingtung, southern Taiwan. The feasibility study phase of the Artificial Recharge of Groundwater Project (ARGP) for Pingtung, Taiwan, was then implemented in 1997 using a MODFLOW simulation and an optimal model. Through the managed aquifer recharge model, the aquifer storage increases and the inundation scale decreases at land subsidence of the coastal area as aimed at by the purpose of the controlled groundwater level. Infiltration mechanism simulation of artificial groundwater recharge, with the TOUGH2 model, was used to simulate the high infiltration behaviour in sequence in 2010. Both publications have been confirmed and approved by the Central Government and then approved by the environmental impact assessment. The ARGP was then implemented in May 2018 and operated for one wet season for the first phase with 50 ha of a total of 300 ha from May to October 2018. The sedimentation over the top of the recharge basin forms the clogging mechanism which has been analysed. The operation experience can further provide the mechanism process for research reference and improved suggestions. Figure 1 shows the location of the project area and hydrological profile of ARGP (NPUST, 2016).

This project is divided into two phases. The first phase of the project was completed in May 2018. The second phase of the project will continue after initial actual onsite operational testing and future operations and facility improvements. The project is aimed at land subsidence control, soil and water conservation, integrated use of surface water and groundwater resources, flood control and disaster mitigation. The planned recharge volume is $150 \mathrm{MM}^{3} \mathrm{yr}^{-1}$, which is based on the recharge rate of $10 \mathrm{~m} \mathrm{~d}^{-1}$ (Pingtung County Government, 2010). The first phase of the project has completed the water intake project, water conveyance project, regulation pond project, and solid sedimentation pond project.

\section{The Artificial Recharge of Groundwater Project}

\subsection{Engineering planning}

The Linbian River is located in the southern part of Pingtung, Taiwan. The catchment of the basin area is $343.97 \mathrm{~km}^{2}$, the river is $42.19 \mathrm{~km}$ in length, and the average slope is ca. $1: 15$. The average annual rainfall of the basin is $3330 \mathrm{~mm}$. The average annual runoff is $854 \mathrm{MM}^{3}$. The ARGP (Pingtung County Government, 2008) is located in the proximity of the alluvial fan in the Linbian River in southeastern Taiwan (Fig. 2). The schematic section of the hydrogeological conceptual model is shown in Fig. 3.

In terms of the planning of CTCI (2003), the ARGP carried out field test results in 2001, the recharge rate was 17 to
$22 \mathrm{~m} \mathrm{~d}^{-1}$, and $10 \mathrm{md}^{-1}$ was taken as the design basis from the water intake. The scale of water intake and water delivery channel is set to $116 \mathrm{cms}^{-1}$ (cubic meters per second, and the recharge basin size is calculated to be ca. 100 ha. It was calculated from the daily river discharge record of the Linbian River in the past 50 years. On average, ca. $150 \mathrm{MM}^{3}$ of river water per year can be used to recharge aquifer in the plain. Since the coastal area of the plain is the main subsidence area of Taiwan, it is expected to have the function of preventing seawater intrusion and mitigating the subsidence of the coastal area.

\subsection{The plan summary}

According to Bouwer (1999)'s proposal, the ARGP is to start small and simple, be learn as you go, and expand as needed. The overall plan for the ARGP was implemented in two phases. The first phase of the project was completed in 2018 , while the second phase of the project will be based on the site operation test and effectiveness evaluation and will then adjust its design parameters and scale to be implemented in sequence.

\subsubsection{Phase 1 project plan}

The current project includes the water intake, water conveyance channel, regulation pond, first sedimentation pond, second sedimentation pond and recharge basin of the project area (Fig. 4). The water intake system adopts the lateral curve method. The reduction of the high turbidity of the water source into the recharge basin area was achieved by taking the surface water designed as $348 \mathrm{cms}^{-1}$; the managed groundwater source can be taken as ca. $116 \mathrm{cms}^{-1}$ by model simulation. The results are shown in Figs. 5 and 6.

\subsubsection{The second phase of the project}

According to the plan in 2003 , the sedimentation pond size needs to be 50 ha; it is thus necessary to set up an 18 ha sedimentation pond in the second phase. The sedimentation pond has a planned depth of $15 \mathrm{~m}$ with a storage capacity of $6.75 \mathrm{MM}^{3}$, which is mainly to precipitate suspended particles of less than $0.3 \mathrm{~mm}$ to avoid siltation from the recharge basin. With the high concentration of sand-bearing river water introduced during the flood season, the concentrates on the sedimentation pond can settle down. On the one hand, the sedimentation can be accelerated because at the bottom of the pond a clay cake layer formed. The recharge rate will be decreased by physical clogging. In the second phase, a 100 ha recharge basin will be set up in a total area of 250 ha to ensure that the amount of infiltration in the aquifer reaches $150 \mathrm{MM}^{3} \mathrm{yr}^{-1}$. 

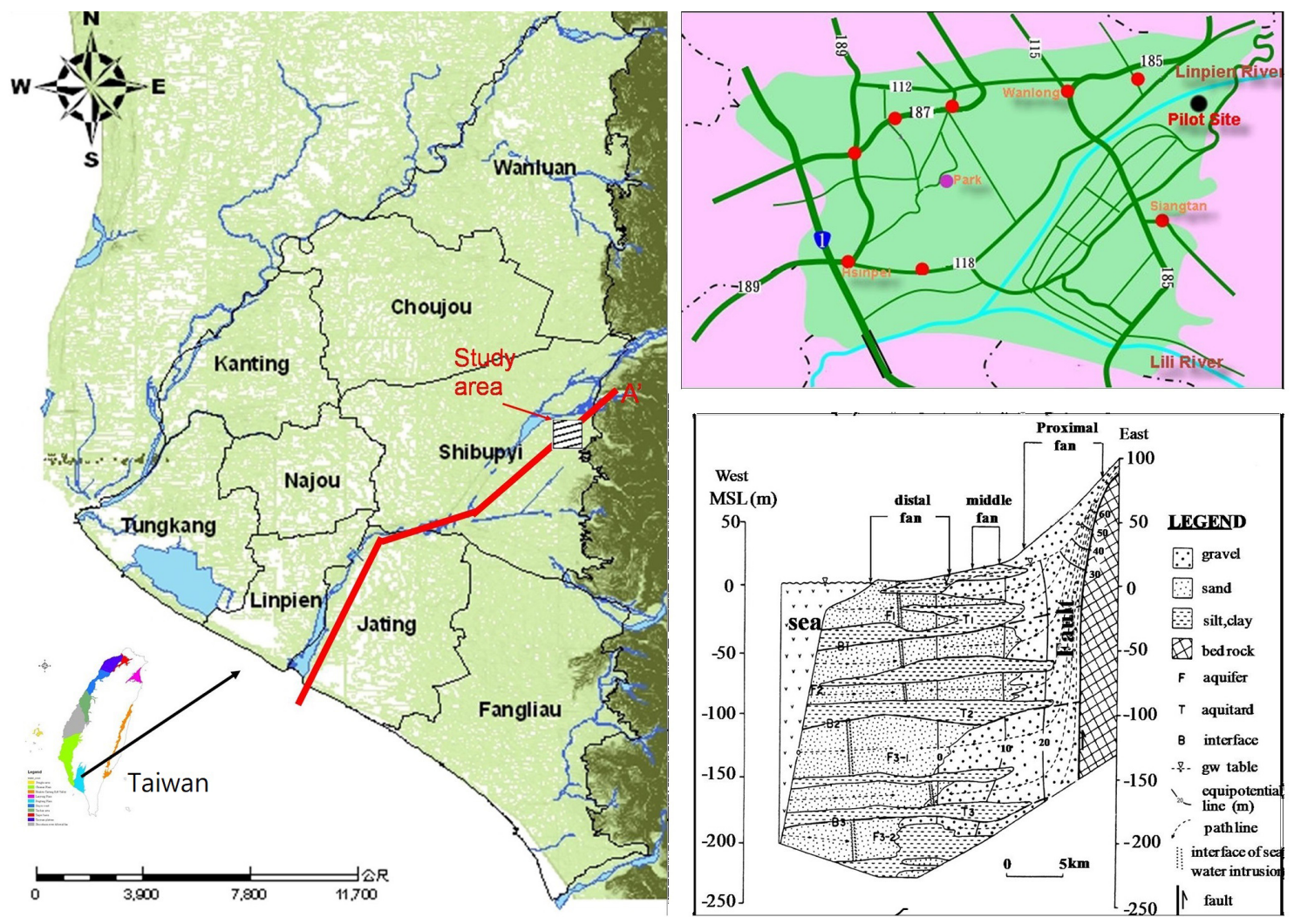

Figure 1. Location of the study area and hydrological profile in the study area (NPUST, 2016).

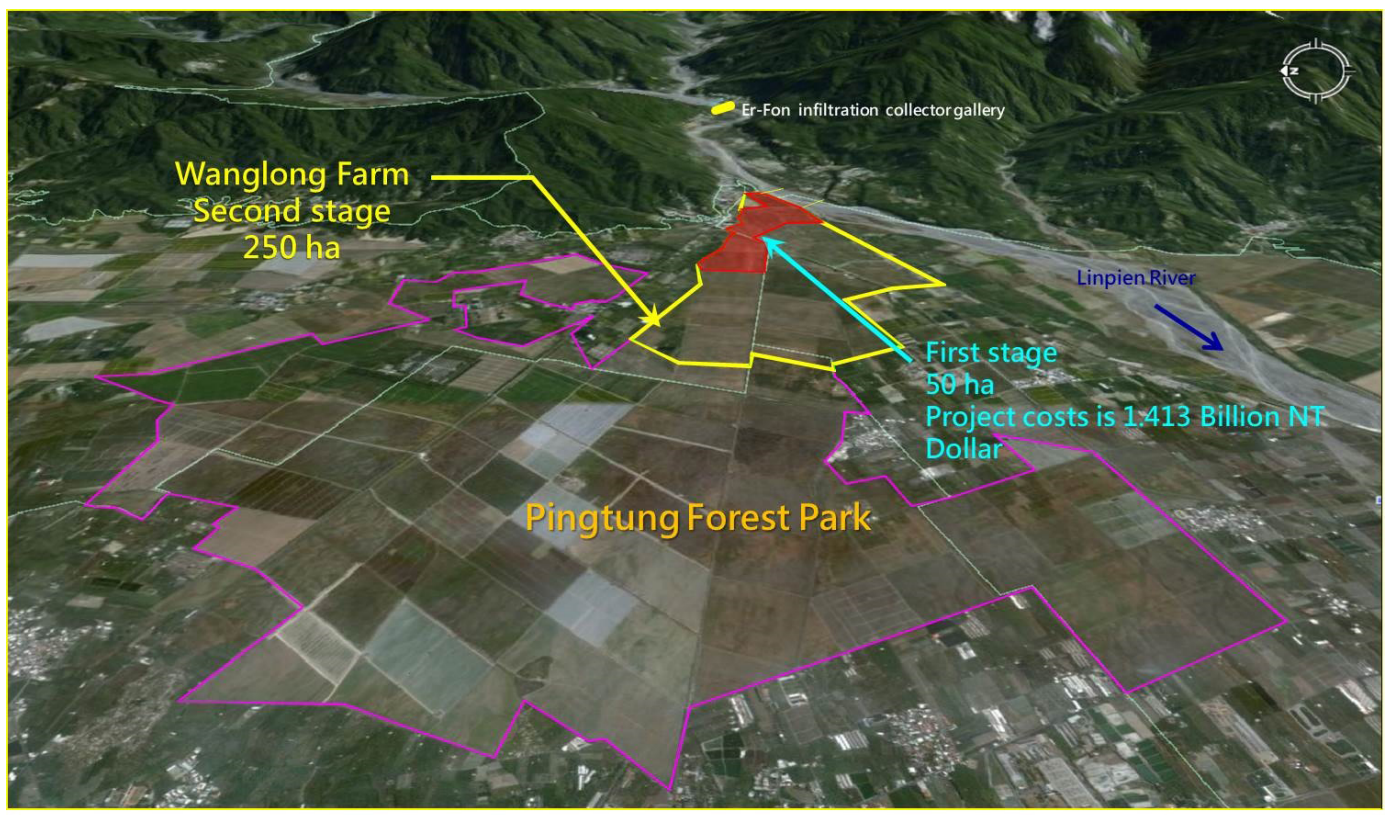

April 13, 2001 to start planning

September 17, 2002 completed the planning

November 13, 2003 passed and awarded the environmental impact assessment review

Figure 2. Location map of the Artificial Recharge of Groundwater Project implemented in Pingtung, Taiwan (Pingtung County Government, 2008). 


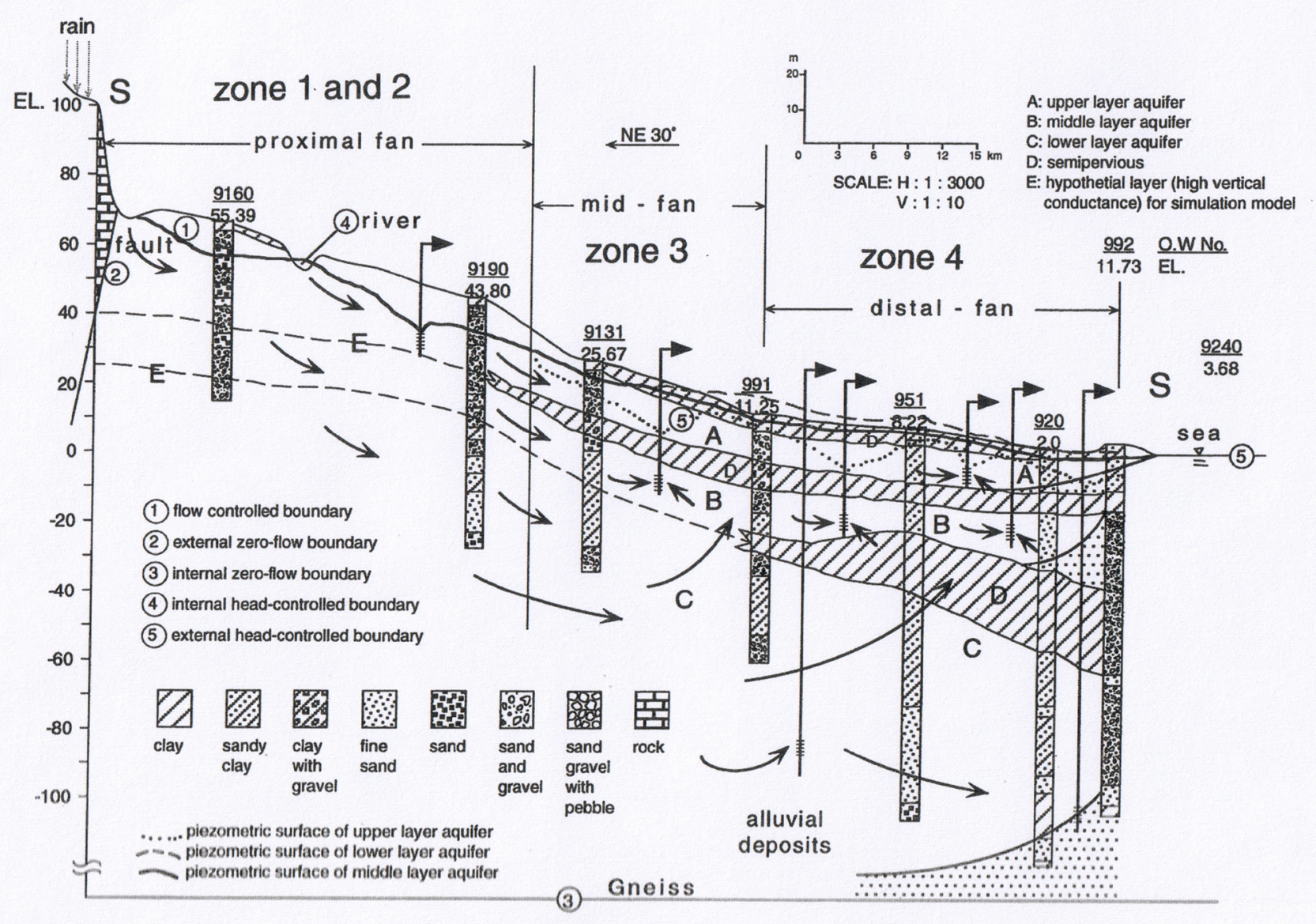

Figure 3. Schematic section of the hydrogeological conceptual model (Ting, 1997).

\section{Preliminary operation and benefit assessment}

In order to understand the regular operation of the groundwater, recharge facilities have already been set up for operational use and for special monitoring needs. The preliminary operational tests were conducted from July to October 2016. However, most of the monitoring systems have been installed. The tests at this stage have been carried out for measurements of river discharge and the regulation pond, sand content of river water, and groundwater tables of the affected area.

The test has been fulfilled in the periods from 25 July to 21 October 2016. The evaluation results showed that the recharge rate of ca. 1 to $5 \mathrm{~m} \mathrm{~d}^{-1}$ of the regulation pond is estimated for which the gradually cumulated sedimentation in the pond runs for ca. $400 \mathrm{~h}$ with a sedimentation volume of ca. 16.8 MM3.

\section{Conclusions}

The project is positioned as studies of the land subsidence of coastal Taiwan and increasing water demand for multipurpose needs. It is expected that the ARGP will have the following expected benefits after preliminary operation.

\subsection{Groundwater resource development benefits}

According to the planning phase report on the MODFLOW model simulation study, the water source after the managed aquifer recharge can be used for the mitigation of the subsidence in the coastal area of the distal alluvial fan to enhance the groundwater level. In addition, using the Hill method to analyse the water resource allocation for multiple use, it can provide a water source of ca. $160000 \mathrm{~m}^{3} \mathrm{~d}^{-1}$ for public water use for all seasons as well. 


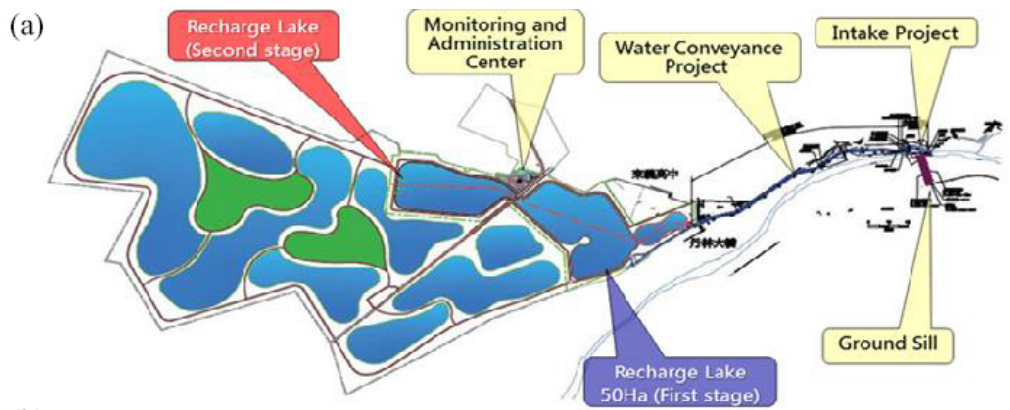

(b)
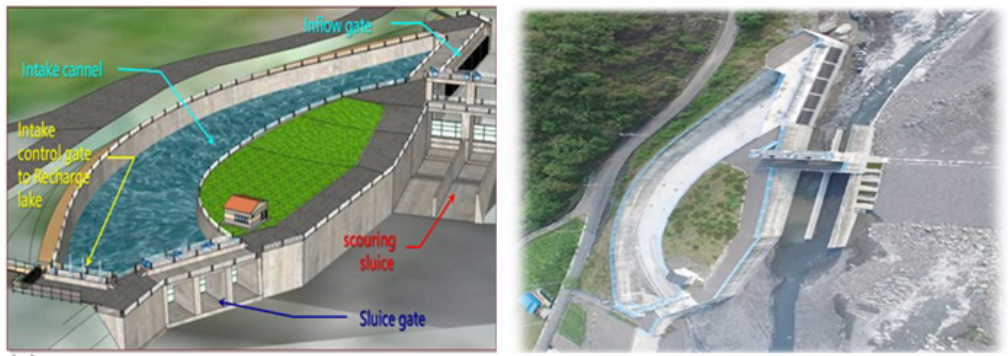

(c)
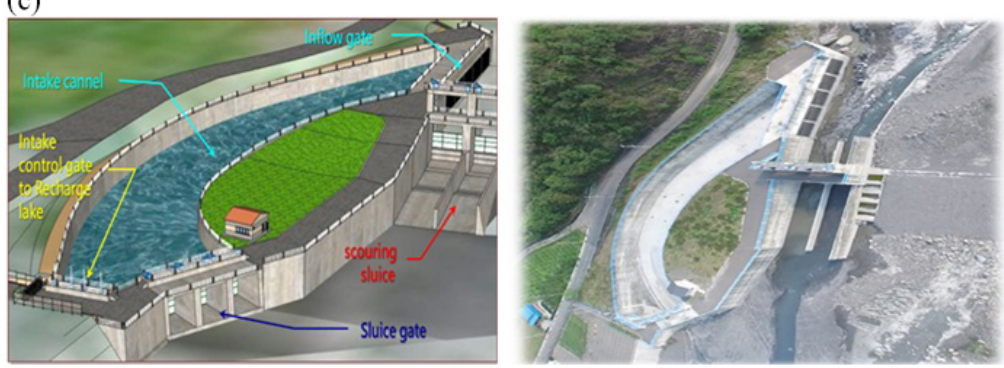

(d)
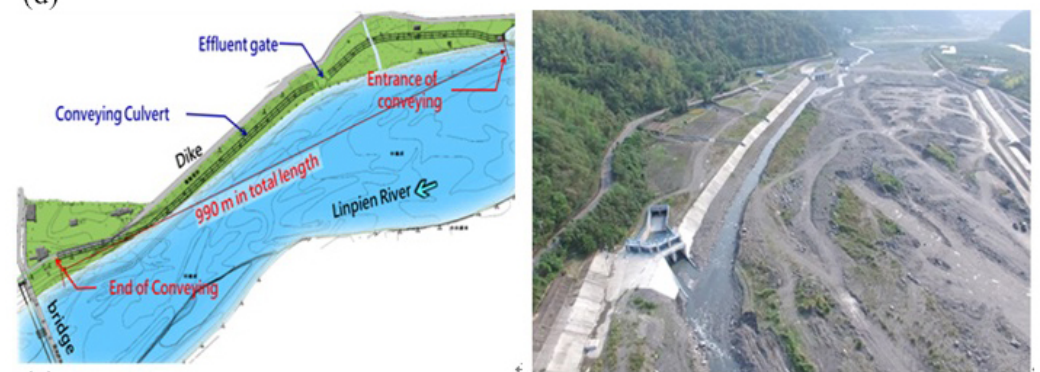

(e)
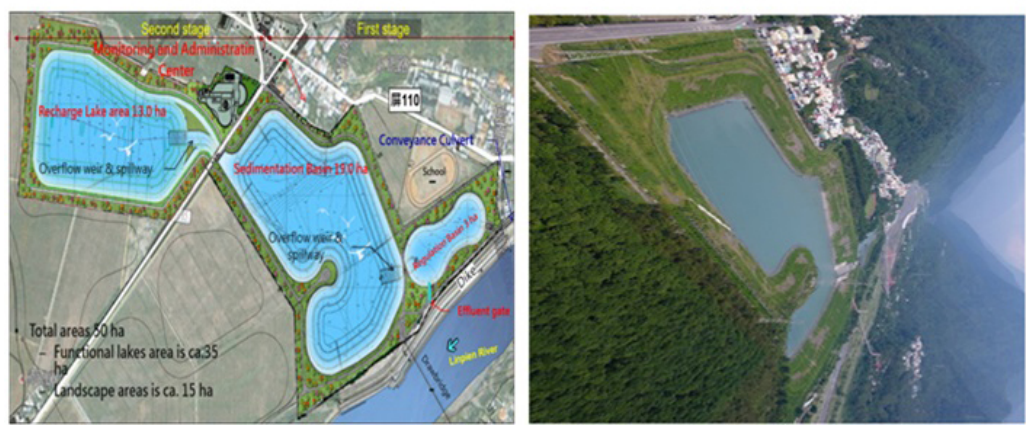

Figure 4. Engineering works of the Artificial Recharge of Groundwater Project (Pingtung County Government, 2010). (a) Engineering works map of the Artificial Recharge of Groundwater Project (Pingtung County Government, 2010). (b) Intake works and ground sill of the Artificial Recharge of Groundwater Project (Pingtung County Government, 2010). (c) Intake works of the Artificial Recharge of Groundwater Project (Pingtung County Government, 2010). (d) Water conveyance channel of the Artificial Recharge of Groundwater Project (Pingtung County Government, 2010). (e) Sedimentation basin (pond) of the Artificial Recharge of Groundwater Project (Pingtung County Government, 2010). 

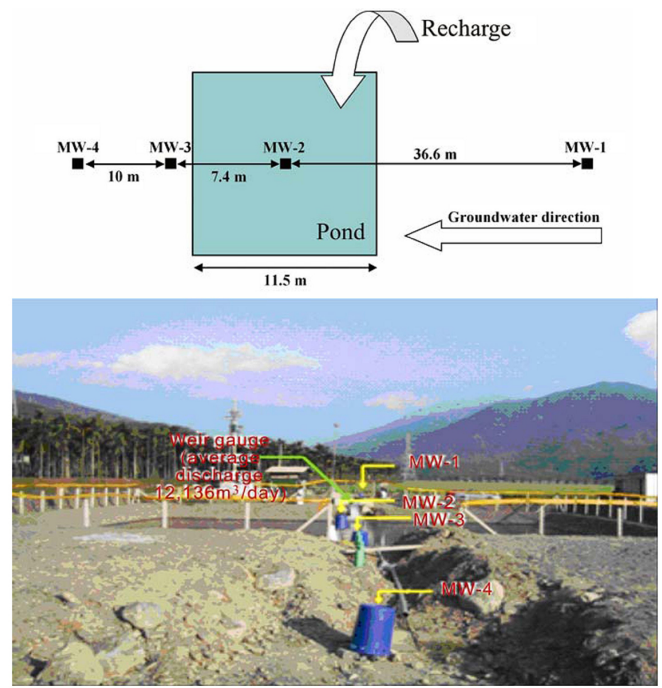

(b)

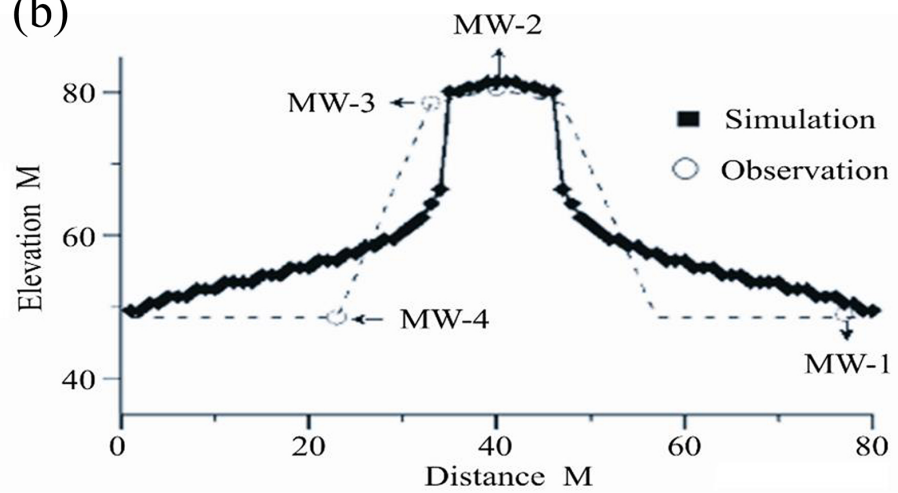

Figure 5. Artificial groundwater recharge using the TOUGH2 model. (a) Infiltration mechanism simulation of artificial groundwater recharge using the TOUGH2 model. (b) Infiltration mechanism simulation of artificial groundwater recharge using the TOUGH2 model.

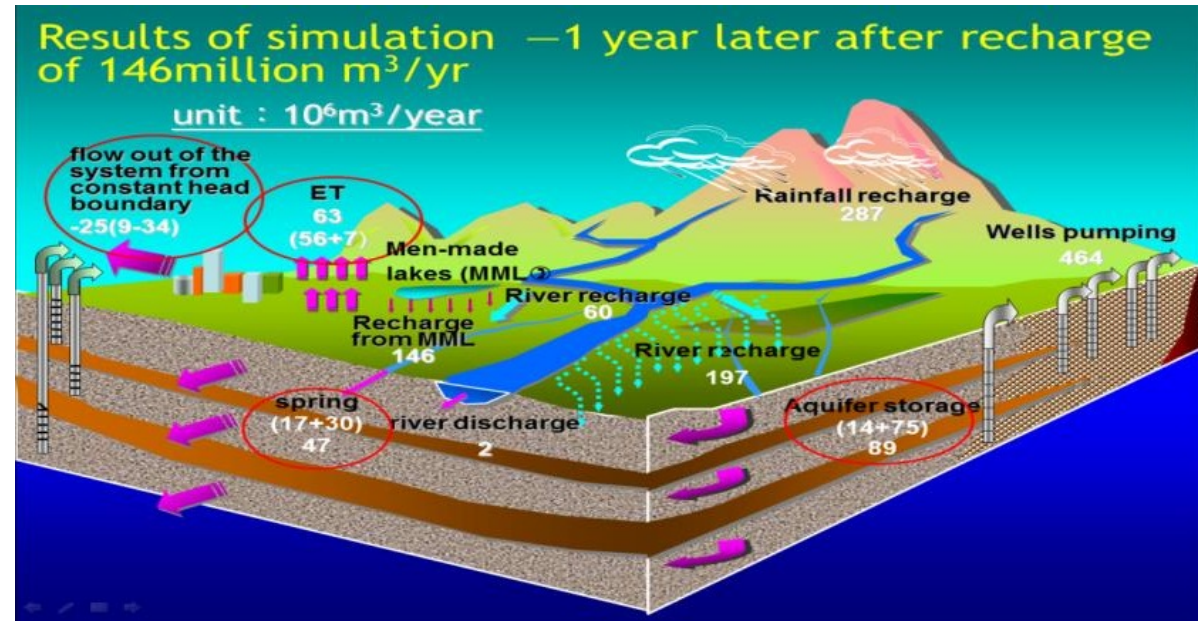

Figure 6. Artificial groundwater recharge using the MODFLOW model (CTCI, 2003). 


\subsection{Benefits of land subsidence}

The formation of land subsidence has a non-recoverable mechanism, and it is impossible to recover it by the groundwater level increased from the ARGP, even with the influence of the groundwater recharge basin. The land subsidence of the stratum is mainly controlled by the groundwater level, and the groundwater level is no longer lower than the precompacting water level; the subsidence of the stratum will thus not continue to deteriorate.

\subsection{Flood diversion and flood reduction benefits}

The ARGP has the function of flood diversion in the upper stream of the Linbian River and reduces flood disasters in the middle and lower streams of the Linbian River during the flood period from May to October. According to the analysis, the peak discharge of the 100-year frequency near the water intake is $1248 \mathrm{cms}^{-1}$, and the design of the water intake of the project is $116 \mathrm{cms}^{-1}$, which has the effect of diverting part of the instantaneous discharge from the river flood.

Data availability. The following source contains data use permission from the authors and the Pingtung County Government: https: //www.pthg.gov.tw/Default.aspx.

Author contributions. CST developed the research framework and implementation and wrote the article. KFC and SHH selected the research site and provided technical planning and administrative support. CHT provided research concept guidance. $\mathrm{CHC}$ created the graphs in the article.

Competing interests. The authors declare that they have no conflict of interest.

Special issue statement. This article is part of the special issue "TISOLS: the Tenth International Symposium On Land Subsidence - living with subsidence". It is a result of the Tenth International Symposium on Land Subsidence, Delft, the Netherlands, 17-21 May 2021.
Acknowledgements. The authors express sincere gratitude for support funding for parts of the early research projects from the Ministry of Economy and Ministry of Science and Technology.

Financial support. This research has been supported by the Pingtung County Government, Taiwan (grant no. D-105-0512-141-1).

\section{References}

Bouwer, H.: Artificial recharge of groundwater: system, design, and management, in: Handbook of Hydraulic design, edited by: Mays, L. W., McGraw-Hill, New York, US, 1999.

CTCI: Pingtung County Water Resources Development and Conservation Overall Planning and Linbian River, Artificial Recharge of Groundwater, Planning Report (6 volumes), Pingtung County Government, Pingtung, Taiwan, 2003.

National Pingtung University of Science and Technology (NPUST): Development Plan for the First Phase of the Artificial Recharge of Groundwater Project in the Year of 2015 - A Report on the End of the Hydrological Data Analysis and Evaluation Project, Pingtung County Government, Pingtung, Taiwan, 2016.

Pingtung County Government: The Land Rehabilitation Project of the Lower Diversion Area of Pingtung County - The Implementation Plan of the First Phase of the Artificial Recharge of Groundwater Project (Approved Version), Pingtung, Taiwan, 2008.

Pingtung County Government: Artificial Recharge of Groundwater Project Phase 1 Project Implementation Planning Project Design Entrusted Technical Service - Engineering Basic Design Report, Pingtung, Taiwan, 2010.

Ting, C.-S.: Groundwater Resources Evaluation and Management for Pingtung Plain, Taiwan, PhD thesis, Free University Amsterdam, the Netherlands, 1997.

Tu, Y.-C., Ting, C.-S., Tsai, H.-T., Chen, J. W., and Lee, C.-H.: Dynamic analysis of the infiltration rate of artificial recharge of groundwater-a case study of Wanglong Lake, Taiwan, Environ. Earth Sci., 63, 77-85, https://doi.org/:10.1007/s12665-0100670-8, 2010. 